\title{
A importância das informaçóes aferentes podais para o controle postural
}

\author{
Feet Afferent Information Importance to Postural Control
}

\section{Marcela Regina de Camargo ${ }^{1}$, Cristina Elena Prado Teles Fregonesi ${ }^{2}$}

\begin{abstract}
RESUMO
Introduçáo. $\mathrm{O}$ controle postural envolve um mecanismo complexo de conexão das vias aferentes e eferentes e sua integração no sistema nervoso central (SNC). Três sistemas são responsáveis pela captação de informação exterior: o visual, o vestibular e o sensorial. Estudos recentes têm demonstrado que, dentre tais sistemas, o SNC demonstra maior predileção às informaçóes sensoriais o controle postural. Objetivo. Diante disso, essa revisão propóe discutir a importância entre as informaçôes sensitivas podais e seu reflexo no mecanismo de controle postural. Método. Para isso, foi realizada uma busca na literatura, através das bibliotecas PubMed e Bireme, e selecionados artigos dos últimos cinco anos. Alguns livros específicos da área também foram utilizados. Discussáo. Os estudos obtidos foram separados em tópicos sobre "integração das informaçóes sensoriais para a resposta neuro-motora"; "recrutamento dos mecanismos de ajustes posturais antecipatórios"; "coordenação e sinergia das respostas neuro-musculares" e "o papel das estruturas teciduais musculoesqueléticas”. Conclusáo. Apesar do grande número de estudos encontrados, permanece obscuro o real mecanismo que o SNC utiliza para filtrar, integrar e processar a informaçáo sensorial e selecionar a reposta motora adequada, seja ela para o movimento ou para a estabilização postural.
\end{abstract}

Unitermos. Postura, Pé, Propriocepção, Sensação.

Citaçáo. Camargo MR, Fregonesi CEPT. A importância das informações aferentes podais para o controle postural.

\begin{abstract}
Introduction. The postural control involves a complex mechanism for connecting the afferent and efferent pathways and their integration into the central nervous system (CNS). Three systems are responsible to obtain outside information: visual, vestibular and sensory. Recent studies have shown that among such systems, the CNS shows a greater predilection for sensory information to postural control. Objective. Given this, the review proposes to discuss the feet sensory information importance and its reflection in postural control mechanisms. Method. For this reason, a literature search was carried out by PubMed and Bireme libraries, and papers of the last five years were selected. Specific books were also used. Discussion. Studies were separated into topics on "sensory information integration to neuro-motor answer", "postural feedforward adjustments recruitment mechanisms"; "neuro-muscular coordination and synergy responses" and "the musculoskeletal tissues role". Conclusion. Despite has been found a large number of studies, the real mechanism that the CNS uses to filter, integrate and process the sensory information and select the appropriate motor response, be it for the movement or posture for the stabilization remains obscure.
\end{abstract}

Keywords. Posture, Foot, Proprioception, Sensation.

Citation. Camargo MR, Fregonesi CEPT. Feet Afferent Information Importance to Postural Control.
Trabalho realizado na Faculdade de Ciências e Tecnologia - Universidade Estadual Paulista - Campus de Presidente Prudente (FCT/UNESP), Presidente Prudente-SP, Brasil.

1. Fisioterapeuta, Mestranda em Fisioterapia - FCT/UNESP, Presidente Prudente-SP, Brasil.

2. Fisioterapeuta, Doutora, Professora Assistente do Curso de Graduaçáo e do Programa de Pós-Graduação Stricto Sensu em Fisioterapia - FCT/ UNESP, Presidente Prudente-SP, Brasil.
Endereço para correspondência: Marcela R Camargo

Departamento de Fisioterapia

R Roberto Simonsen, 305 CEP 19060-900, Presidente Prudente-SP, Brasil. Tel: (18) 3229-5365 - Ramal 213 E-mail: amy.marcela@gmail.com 


\section{INTRODUÇÃO}

A manutenção da postura envolve o controle da posição do corpo no espaço com objetivo duplo de estabilidade e orientação. $\mathrm{O}$ estabelecimento postural se dá através de um balanço entre sinergias neuro-musculares, estratégias sensoriais, mecanismos antecipatórios e adaptativos, representaçóes internas e componentes periféricos. É, portanto, exigida uma complexa integração entre sistema musculoesquelético, como a amplitude de movimento (ADM) das articulaçóes; flexibilidade da coluna; propriedades musculares; relaçóes biomecânicas entre os segmentos corpóreos; e propriedades neurais, como os processos sensoriais, motores e de integração $0^{1,2}$.

As informaçóes sensoriais são provenientes do sistema visual, vestibular e somatossensitivo. Esses três tipos de aferências estão integrados e são processados para elaboração da resposta de ajuste e controle postural. Muitos estudos demonstram que a informação somatossensitiva é, com frequência, a mais utilizada pelo sistema nervoso central (SNC). Sendo assim, pode-se inferir que, aparentemente, o SNC dá maior preferência às aferências somatossensitivas ao realizar reajustes posturais, pois essas aferências atuam informando ao SNC a relação entre os diferentes segmentos do corpo. Isto ocorre através dos proprioceptores - fusos musculares, órgãos neurotendíneos e receptores articulares e através de mecanoceptores cutâneos - corpúsculos de Paccini e discos de Merckel, principalmente ${ }^{1-3}$.

Nos pés, além das aferências desencadearem reflexos segmentares, as vias proprioceptivas e cutâneoplantares, através do sistema epicrítico, emitem ramos colaterais para o cerebelo e para estruturas romboencefálicas de propriocepção inconsciente. Isso permite que as informações provenientes dos mesmos proprioceptores sejam processadas simultaneamente pelo SNC, que, por sua vez, transmite informaçóes aos músculos agonistas ou antagonistas, conforme se articulem com interneurônios excitatórios ou inibitórios. Esse fato aperfeiçoa as respostas de adaptação postural e torna os pés uma excelente ferramenta de informaçáo aferente proprioceptiva ${ }^{4,5}$.
Diante disso, o presente estudo propóe realizar uma revisão de literatura sobre a influência da condução de informação aferente somatossensitiva proveniente dos pés no controle postural, bem como discutir as possíveis relações entre as variâncias desta informação e o desenvolvimento do padrão postural individual.

\section{MÉTODO}

Para realização da presente revisão de literatura, foi executada uma busca de artigos nas bibliotecas PubMed e Bireme, acessando as bases de dados MEDLINE, LILACS e SciELO. Foi, então, realizado o cruzamento entre os descritores de assuntos pé x postura, em sites de busca por língua portuguesa, e foot $x$ posture, em sites de língua inglesa. Os estudos incluídos passaram pelos seguintes critérios de seleção: abordagem direta do tema, idiomas inglês e português, data de publicação entre 2004-2008 e disponibilidade eletrônica. Foram incluídos artigos experimentais - com delineamento, critérios de exclusão, e aspectos éticos claramente explicitados no texto; e estudos de revisão - com tema diretamente relacionado ao assunto, dessa forma, foram selecionados estudos que relacionavam a entidade neurofuncional dos pés, sendo descartados aqueles com enfoque puramente ortopédico. Além desta busca, o presente estudo abrangeu alguns livros diretamente relacionados com o assunto.

\section{DISCUSSÃO}

Sabe-se que durante a infância, período de amadurecimento neuro-sensório-motor, cada nova experiência aprimora os padróes de controle postural. $\mathrm{O}$ desenvolvimento, fixação e manutenção destes padróes são de crucial importância para realização das atividades de vida diária do adulto. Assim, conforme ocorre movimentação corpórea, deve existir uma resposta auxiliadora dos sistemas de referência (visual, vestibular e somatossensitivo) de modo com que ocorra adaptação das novas posturas promovendo a manutenção do equilíbrio ${ }^{6-8}$.

Este mecanismo de ajuste do sistema sensorial permanece durante toda a vida do indivíduo. Contu- 
do, por já ter sido desenvolvido, durante a infância, mecanismos antecipatórios (feed-forward), as respostas sensoriais do adulto são mais maduras e específicas para cada perturbaçáo postural. As informaçóes provenientes do sistema somatossensitivo têm grande influência para a elaboração da resposta neuro-motora de ajuste e serão enfocadas nesta revisão.

Integração das informaçóes sensoriais para a resposta neuro-motora:

Ainda não há unanimidade em relação à exata maneira que o SNC utiliza para integrar e processar a informação sensorial. Alguns estudos concordam que a resposta motora reflete a influência de entradas sensoriais múltiplas, enquanto outros autores defendem que um tipo de informação sensorial domina o mecanismo?.

A controvérsia entre os estudiosos enfoca-se especificamente em saber se o SNC controla o equilíbrio, como forma de manutenção da postura, através de um mecanismo compensatório (feedback), gerando forças musculares para respostas de correçáo automática de equilíbrio, ou se açóes antecipatórias (feed-forward) também são requeridas para manter a postura em pé $^{10}$.

$\mathrm{O}$ sistema nervoso possui um mecanismo pelo qual os neurônios mais ativos limitam a atividade dos neurônios adjacentes menos ativos, assegurando que apenas uma entre duas respostas competitivas seja expressa. Este fato contribui para a percepção seletiva da sensação. Além disso, o próprio córtex motor e o tronco cerebral podem inibir e controlar o fluxo de informação sendo, portanto, capazes de controlar as informaçôes provenientes da periferia ${ }^{11}$.

No caso do controle postural, as formas de integração náo se aplicam apenas às informaçóes provenientes de diferentes sentidos sensoriais, mas podem ocorrer mesmo quando dois estímulos afetam um único canal sensorial, suprimindo ou utilizando as informaçóes, de acordo com a sua contribuição, benéfica ou prejudicial, para o controle da postura ${ }^{12}$. Isto demonstra a grande adaptabilidade do SNC em avaliar rapi- damente as diversas dicas sensoriais e seu potencial de utilização para manutenção da estabilidade postural.

A idéia de que o SNC ajusta seletivamente as diversas contribuiçóes sensoriais para uma resposta motora é confirmada por um estudo ${ }^{13}$, que ainda ressalta que grande parte dessas contribuiçóes é de responsabilidade dos proprioceptores dos tornozelos e mecanoceptores plantares. Além disso, a resposta somatossensitiva para o controle postural varia de um sujeito a outro, sendo este um fator importante que sempre deve ser considerado ${ }^{14}$.

Um estudo ${ }^{15}$, que isolou a resposta de feedback dos aferentes cutâneo-plantares por anestesia, concluiu que essa reposta é extremamente necessária para a manutenção do equilíbrio normal quando os proprioceptores e visão estão comprometidos. Ficou comprovado, então, que as informaçóes provenientes dos mecanoceptores cutâneos têm importância relativa para o ajuste postural. Todavia, quando há comprometimento de um ou mais aferente sensorial, esta informação se torna crucial para o controle do equilíbrio e da postura.

Recrutamento dos mecanismos de ajustes posturais antecipatórios:

Aparentemente, os ajustes posturais antecipatórios influenciam na estabilidade postural, no desempenho e tipo de movimento isolado e na posição inicial do centro de massa $(\mathrm{CM})^{1}$. A duraçáo destes ajustes é fixada de acordo com o deslocamento do CM inicial, estimado pelos aferentes cutâneo-plantares antes do início de um passo, podendo estar diretamente envolvida tanto pelo aumento de força de suporte do membro inferior durante o apoio, quanto pelo acréscimo da força propulsora para remoção do calcanhar do solo no início da fase de balanço da marcha ${ }^{16}$.

Existem duas estratégias recrutadas de maneira isolada ou simultânea pelo SNC para a manutenção do CM. A estratégia de tornozelo é utilizada para reposição do CM através do movimento do corpo - principalmente em torno do tornozelo - com um discreto movimento do quadril. Essa estratégia é observada em 
respostas às perturbaçóes relativamente lentas, necessitando da integridade da amplitude e força muscular da articulação do tornozelo. Já a estratégia de quadril controla o CM por meio da produção de um movimento amplo e rápido no quadril, com rotação antifase do tornozelo, ou seja, combinação de extensão de quadril com dorsiflexão de tornozelo ou flexão de quadril com plantiflexão de tornozelo ${ }^{1,17}$.

O tipo de organização postural a ser adotado não é determinado apenas pelas articulaçôes envolvidas, mas sim pela maneira pela qual os movimentos das diferentes articulações são coordenados. Existem três categorias de restriçóes que influenciam os modos de coordenação do movimento: as limitações ambientais, como as irregularidades do terreno; propriedades intrínsecas, como a altura do centro de massa e o comprimento dos pés; e restrições intencionais ou da tarefa, como a execução da orientação para acompanhamento do movimento de um alvo ${ }^{18}$.

Em um estudo ${ }^{19}$ de intervenção fisioterapêutica em idosos foi observada melhora do parâmetro baropodométrico. Esse ganho foi relacionado a um aumento das aferências cutâneo-plantares e consequente facilitação do controle motor e estabilidade postural. Este fato pode acabar favorecendo a estabilidade para realização da marcha, tornando essa população menos propensa às quedas.

Em outro estudo ${ }^{20}$, com indivíduos que apresentavam déficits proprioceptivos, foi concluído que, mesmo em pessoas que não demonstram apresentar déficit sensorial, uma fonte adicional de informação sensorial pode melhorar o desempenho postural. Assim, a disponibilidade destas informaçóes aos sujeitos que apresentam perda oferece melhora significativa para o controle da postura.

Podemos concluir, então, que a atividade dos músculos posturais, observada principalmente nos músculos extensores dos membros inferiores e nos músculos do tronco e pescoço, objetiva a manutenção da projeção do centro de gravidade (CG) dentro dos limites da base de apoio ${ }^{21}$. A partir daí, pode-se deduzir que as aferências proprioceptivas têm um grande papel nesse contexto, mas não se pode descartar a importância da integridade do mecanismo de discriminação cutâneo-plantar. Tal mecanismo deve facilitar o SNC a detectar as projeções do CG e, desta forma, permitir uma diminuição da oscilação corporal na manutenção da postura ${ }^{22}$.

Coordenaçâo e sinergia das respostas neuro-musculares:

As repostas compensatórias de ajuste postural têm uma ampla diferença quando comparadas às respostas de antecipação. As repostas de feedback podem ser realizadas por um circuito relativamente simples de arco reflexo, enquanto as respostas de feed-forward necessitam de acesso a um circuito de armazenagem de padrôes de ativação muscular. Uma resposta compensatória tem maior relação na manutenção do corpo em posição ereta, estática e dinâmica. Em contrapartida, o mecanismo de feed-forward tem maior participação em resposta a uma perturbação ${ }^{23}$.

O sistema nervoso é responsável pelas repostas de sinergia e coordenação de ativação muscular através dos mecanismos supracitados e a anatomia dos membros inferiores permite que as forças de reação estejam vinculadas, em grande parte, aos quadris e tornozelos. Estas articulaçóes são responsáveis por controlar os movimentos corporais, quer seja no plano frontal ou no plano sagital ${ }^{24}$.

A estratégia do tornozelo pode ser denominada como fase padrão (tornozelo e quadril deslocando-se na mesma direção) e a estratégia de quadril como fase antipadrão (tornozelo e quadril em direções opostas). A coordenação dessas estratégias depende do envio de informaçóes dos proprioceptores articulares e, se ocorrer um distúrbio na transmissão de informação somatossensitiva proveniente dos aferentes de pés e tornozelo, o SNC envia informaçóes para uma redistribuição do torque para os quadris ${ }^{15,25}$. Pode-se inferir, então, que este fator altere todo o sistema de fases padrão e antipadrão, provocando déficits de ajuste.

Quando se transfere este quadro fisiológico às enfermidades mais comumente encontradas, como as 
neuropatias periféricas, além do comprometimento dos proprioceptores, há uma alteração de condução nervosa aferente dos mecanoceptores cutâneos. Esta perda global de sensibilidade podal acarreta alteração no tempo de ativação de alguns músculos posturais do membro inferior e diminuição do reflexo miotático, piorando o controle postural26.

\section{O papel das estruturas teciduais musculoesqueléticas:}

Como já mencionado anteriormente, além das estruturas nervosas, contribuem para o sucesso do controle postural, os componentes musculoesqueléticos. Tais componentes - músculos, tendōes, cápsula articular, ligamentos e ossos - são sítios de estruturas responsáveis pelas aferências sensitivas e determinam a execução adequada da resposta motora.

Um estudo sobre o efeito da fadiga muscular nas respostas de controle da postura concluiu que sinais de condução nervosa aferente, durante um estado de fadiga muscular, talvez leve a uma propagação mais lenta dos sinais eferentes para manutenção postural. Consequentemente, sujeitos com fadiga muscular têm maior propensão a lesóes musculoesqueléticas, devido ao atraso de condução nervosa ${ }^{27}$.

O reflexo de alongamento no tornozelo é o mecanismo de maior controle tanto na postura estática, quanto perante a uma perturbação. A rigidez nessa articulação, comum em idosos ou em sujeitos com lesão do SNC, é acrescida pelo aumento do tempo do feedback extramuscular, ocasionado pela co-contração muscular ou por um feedback positivo forçado. Este atraso no mecanismo de arco-reflexo pode explicar a dificuldade dessa população em realizar tarefas com exigência postural ${ }^{28}$.

\section{CONSIDERAÇÕES FINAIS}

Está claro que todas as aferências podais, de alguma forma, colaboram e são priorizadas pelo SNC na resposta de manutençáo e recuperaçáo da postura e equilíbrio no corpo humano. Muito do funcionamento de tal recrutamento, como padróes de sinergia e coordenação, articulaçóes envolvidas em cada resposta específica e o comportamento e adaptaçóes perante lesóes, estão aparentemente esclarecidos. Contudo, apesar da ampla quantidade de estudos encontrados na literatura sobre a real influência das informações somatossensitivas no controle postural, ainda permanecem obscuras algumas informaçóes-chave do mecanismo de adaptabilidade do SNC para filtrar as respostas aferentes e selecionar a resposta motora mais adequada a um estímulo. Pesquisas futuras são necessárias no sentido de melhor entender o mecanismo de aprendizado neuro-sensório-motor, bem como sua adequabilidade às demandas da tarefa e do ambiente.

\section{AGRADECIMENTO}

CAPES - Coordenação de Aperfeiçoamento de Pessoal de Nível Superior; Programa de Pós-Graduação em Fisioterapia da FCT/UNESP e Laboratório de Estudos Clínicos em Fisioterapia (LECFisio) da FCT/ UNESP.

\section{REFERÊNCIAS}

1.Shumway-Cook A, Woollacott MH. O Controle Motor: Teorias e aplicaçōes práticas. São Paulo: Manole, 2003, 610p.

2.Lundy-Ekman L. Neurociência: Fundamentos para Reabilitação. Rio de Janeiro: Guanabara Koogan, 2000, 532p.

3.Souza GS, Gonçalves DF, Pastre CM. Propriocepção cervical e equilíbrio: uma revisão. Fisioterapia em Movimento 2006;19:33-40.

4.Bricot B. Posturologia. São Paulo: Editora Ícone, 2004, 270p.

5.Lent R. Cem Bilhōes de Neurônios: Conceitos Fundamentais de Neurociência. São Paulo: Atheneu, 2005, 698p.

6.Oliveira TP, Santos AMC, Andrade MC, Ávila AOV. Avaliaçăo do controle postural de crianças praticantes e não praticantes de atividade física regular. J Bras Biomecânica 2008;9:41-6.

7.Simoneau M, Richer N, Mercier P, Allard P, Teasdale N. Sensory deprivation and balance control in idiopathic scoliosis adolescents. Exp Brain Res 2006;170:576-82.

8.Suzuki S, Gugelmim MRG, Soares AV. O equilíbrio estático em crianças em idade escolar com transtorno de déficit de atenção/hiperatividade 2005; 18:49-54.

9.Wu G, Haugh L, Sarnow M, Hitt J. A neural network approach to motor-sensory relations during postural disturbance. Brain Res Bull 2006;69:365-74.

10.Alexandrov AV, Frolov AA, Horak FB, Carlson-Kuhta P, Park S. Feedback equilibrium control during human standing. Biol Cybern 2005;93:309-22. 
11.Kandel ER, Schwartz JH, Jessell TM. Fundamentos da Neurociência e do Comportamento. Rio de Janeiro: Guanabara Koogan, 1997, 591p.

12.Hatzitaki V, Pavlou M, Bronstein AM. The integration of multiple proprioceptive information: effect of ankle tendon vibration on postural responses to platform tilt. Exp Brain Res 2004;154:345-54.

13.Vuillerme N, Pinsault N. Re-weinhting of somatosensory inputs from the foot and the ankle for controlling posture during quiet standing following trunk extensor muscles fatigue. Exp Brain Res 2007;183:323-7.

14.Vuillerme N, Chenu O, Pinsault N, Boisgontier M, Demongeot J, Payan Y. Inter-individual variability in sensory weighting of a plantar pressure-based, tongue-placed tactile biofeedback for controlling posture. Neurosci Lett 2007;421:173-7.

15.Meyer PF, Oddsson LIE, De Luca CJ. The role of plantar cutaneous sensation in unperturbed stance. Exp Brain Res 2004;156:505-12.

16.Azuma T, Ito T, Yamashita N. Effects of changing the initial location of the center of mass on the anticipatory postural adjustments and task performance associated with step initiation. Gait Posture 2007;26:526-31.

17.Ferry M, Cahoue V, Martin L. Postural coordination modes and transition: dynamical explanations. Exp Brain Res 2007;180:49-57.

18.Martin L, Cahoue V, Ferry, Fouque F. Optimization model predictions for postural coordination modes. J Biomech 2006;39:170-6.

19.Alfieri FM, Teodori RM, Guirro RRJ. Estudo baropodométrico em idosos submetidos à intervenção fisioterapêutica 2006;19:67-74.
20.Bonfim TR, Barela JA. Efeito da manipulação da informação sensorial na propriocepção e no controle postural 2007;20:107-17.

21.Mouzat A, Dabonneville M, Bertrand P. The effect of feet position on orthostatic posture in a female sample group. Neurosci Lett 2004;365:79-82. 22.Bernard-Demanze L, Burdet C, Berger L, Rougier P. Recalibration of somesthetic plantar information in the control of undisturbed upright stance maintenance. 2004;3:433-51.

23.Park S, Horak FB, Kuo AD. Postural feedback responses scale with biomechanical constraints in human standing. Exp Brain Res 2004;154:417-27. 24.Rougier PR. Relative contribution of the pressure variations under the feet and body weight distribution over both legs in the control of upright stance. J Biomech 2007;40:2477-82.

25.Antoine P, Florent F, Violaine C, Alain M. Effects of plantar flexor muscles fatigue induced by electromyostimulation on postural coordination. Neurosci Lett 2007;414:16-20.

26.Akashi PMH, Sacco ICN, Watari R, Hennig E. The effect of diabetic neuropathy and previous foot ulceration in EMG and ground reaction forces during gait. Clin Biomech 2008;23:584-92.

27.Gribble PA, Hertel J. Effect of hip and muscle fatigue on unipedal postural control. J Electromyogr Kinesiol 2004;14:641-6.

28.Verdaasdonk BW, Koopman HFJM, van Gils SA, van der Helm FCT. Bifurcation and stability analysis in musculoskeletal systems: a study in human stance. Biol Cybern 2004;91:48-62. 